\title{
Zukunft durch Vielfalt
}

Liebe Leserin, lieber Leser,

die Automobilindustrie steht vor großen disruptiven Veränderungen. Die Kernfragen sind: Wie müssen Mobilitätskonzepte aussehen, um urbane Anforderungen auch morgen noch zu erfüllen? Wie muss die Energiekette für den Verkehr aufgebaut sein, um sinnvoll zukünftige Mobilität sicherzustellen? Die Treiber sind Klimawandel, Urbanisierung, Digitalisierung und Automatisierung. So hob SchaefflerTechnologievorstand Prof. Dr. Peter Gutzmer auf dem 11. Schaeffler-Kolloquium in Baden-Baden hervor: „Die autogerechte Stadt wird es nicht geben, wir müssen uns andere Lösungen einfallen lassen. Der intermodale Verkehr wird deutlich zunehmen. Wie schaffen wir also eine effizientere Transportleistung? “ Europa liegt hier noch weit zurück. In anderen Weltgegenden stehen bei Stadtplanungen intelligente und vernetzte Mobilitätslösungen, weitgehende Emissionsfreiheit sowie die Nutzung regenerativer Energie viel stärker im Vordergrund. Es geht auch um die Entzerrung des Verkehrsaufkommens mittels individualisierter, fußgängerorientierter Mobilität - auch mit Robotaxis, Pedelecs oder Fahrzeugen wie dem Bio-Hybrid von Schaeffler.

Bei der Entwicklung zukünftiger Mobilität ist eine ganzheitliche Betrachtung der Energiekette erforderlich. Soll, wie im Pariser Klimaschutzabkommen verankert, die Erderwärmung auf maximal $2{ }^{\circ} \mathrm{C}$ begrenzt werden, muss die Energiewende bis 2030 in allen Sektoren eingeleitet sein. Schaeffler stellte auf dem Kolloquium ein eigenes Szenario vor, das für 2030 einen Flottenmix von $30 \%$ rein elektrischen, $40 \%$ Hybrid- und $30 \%$ konventionell angetriebenen Fahrzeugen als sinnvoll und möglich erachtet. Extrapoliert wären bei diesem Szenario 2050 rund $66 \%$ E-Fahrzeuge im Feld und das $2-^{\circ} \mathrm{C}$-Ziel erreichbar. Die Beurteilung des Antriebsmixes muss mit einer Cradle-to-GraveBewertung erfolgen. „Ganzheitlich betrachtet hat das BEV gegenüber dem PHEV erst ab 120.000 km einen ökologischen Vorteil, denn unter anderem der ökologische Fußabdruck durch die Produktion ist beim BEV erheblich“, so das Fazit von Schaeffler-Forschungschef Uwe Wagner. Da realistisch betrachtet neben E-Antrieben kurzfristig Lösungen für heutige Antriebsstränge realisiert werden müssen, ist die Einführung von E-Fuels neben der Hybridisierung von Verbrennungsmotoren ein wichtiger Schritt, um Emissionen global nachhaltig zu senken. Wenn sich, wie im Schaeffler-Szenario, der Anteil der E-Fuels aus nachhaltigen Quellen bis 2050 auf 80 \% erhöht, dann sind die angestrebten $\mathrm{CO}_{2}$-Werte deutlich zu erreichen. Aber macht es dann Sinn, ein Drittel der zur Verfügung stehenden Energie für Mobilität zu nutzen? Es spricht vieles für einen diversifizierten Antriebsmix mit verbrennungsmotorischen Antrieben, bei dem auch Wasserstoff eine Rolle spielt. Zukunft gestalten heißt Vielfalt zulassen.

Ich wünsche Ihnen viel Spaß bei der Lektüre dieser ATZ.

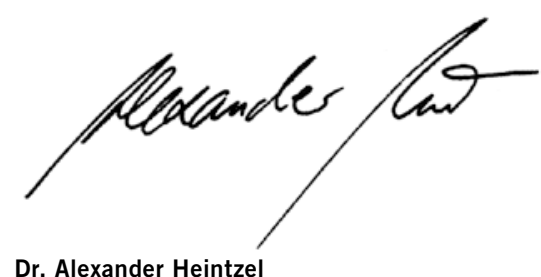

Chefredakteur

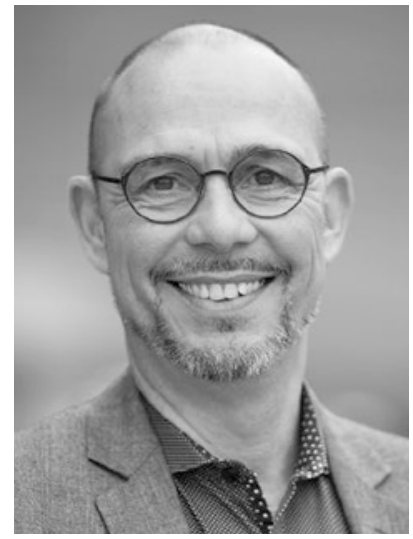

\section{Ihr Partner für den virtuellen Fahrversuch}

\section{Als Technologietreiber die automobile Zukunft mitgestalten}

Mit unseren Lösungen helfen wir als Technologieführer für den virtuellen Fahrversuch unseren Kunden weltweit realitätsgetreue virtuelle Tests im gesamten Entwicklungsprozess gemäß dem Prinzip des Automotive Systems Engineering durchzuführen und somit reale Prototypen einzusparen. 